Dhaka Univ. J. Biol. Sci. 22(1): 55-62, 2013 (January)

\title{
EFFECTS OF TRANSPORT MEDIA AND DURATION ON THE MORTALITY AND PHYSIOLOGICAL RESPONSES IN SILVER CARP HYPOPHTHALMICHTHYS MOLITRIX FINGERLINGS
}

\author{
Mahmud Hasan*, Anwar Hossain, Shankar C. Mandal and Wahida Haque \\ Department of Fisheries, University of Dhaka, Dhaka-1000, Bangladesh
}

Key words: Transport, Media, Silver carp, Mortality, Cortisol, Chloride

\begin{abstract}
This study evaluated the effects of three transport media i.e., well water $(\mathrm{WW})$, pond water (PW) and mixture of the two (WPW; $1: 1)$ and durations $(1,3$, 6 and $9 \mathrm{hrs}$ ) on the mortality and physiological responses in silver carp, Hypophthalmichthys molitrix fingerlings in a transport simulation at $400 \mathrm{~g} /$ loading density. While the total mortality was lower than $9 \%$ until $6 \mathrm{hrs}$ of transport, it was very high $(49-60 \%)$ at 9 hrs across all three treatment media. The highest level of cortisol was measured in the fingerlings simulated using WPW while the lowest level was detected in the fingerlings sampled form WW. The level of cortisol observed in the fingerlings simulated using PW was not different from other two media. Between durations, the levels of cortisol observed were significantly different. The highest chloride level was measured in the fingerlings simulated using WW while the lowest level was observed in the fingerlings sampled from WPW. PW did not result in different chloride level from those of WW and WPW. Among duration treatments, while 9 hrs resulted in the lowest level of chloride, the highest level was detected at $1 \mathrm{hr}$. The results suggest that WW, PW and WPW can be used as medium in transporting well conditioned silver carp fingerlings for $6 \mathrm{hrs}$ with little mortality and less stress effects.
\end{abstract}

\section{Introduction}

Silver carp is an important cultured fish in Bangladesh. The contribution of silver carp in the country's total fish yield is significant ${ }^{(1)}$. Every year millions of silver carp fingerlings are distributed by land transport in traditional method by the fish seed traders. Typically the transport water is manually aerated. Mortality resulting from transport related stress is common which is estimated to be $6200 \mathrm{mt}$ a year ${ }^{(2)}$. Handling and transport related activities could place fish in adverse condition that is responsible for several physiological consequences. However, silver carp fingerlings are the most sensitive to transport mortality ${ }^{(3,4)}$.

*Author for correspondence: <mhasan@univdhaka.edu>. 
Traders use well, pond and the mixture of well and pond water depending on the availability. In most cases, although the traders initially fill the transport container with well water, during transport they use pond water to refill the lost water resulting from violent agitation and/or movement of the truck or change the transport water when it becomes turbid due to liberated mucous and regurgitated stomach contents. Water quality in particular the required oxygen concentration and transport conditions are important factors affecting successful transport ${ }^{(5)}$.

Nabi et al.(6) demonstrated that while river water resulted in $24.00 \pm 5.96 \%$ overall mortality in mixed carp fry in a simulation laboratory experiment, the well and pond water had $11.08 \pm 3.91$ and $15.50 \pm 4.95 \%$. Samson and Macintosh $(1986)^{(5)}$ observed $6.45 \%$ mortality in unconditioned silver carp fry $(0.25 \mathrm{~g})$ using well water and $15 \%$ using pond water $3 \mathrm{hrs}$ after closed transport with compressed oxygen. However, the effects of water medium and duration on the mortality and physiological responses in silver carp fingerlings at high density ( $400 \mathrm{~g} \Lambda$ ) have not been reported. The current study evaluated the effects of well water, pond water and a mixture of both on the silver carp fingerlings. The objectives of this study were to determine the mortality, and to assess the plasma cortisol and chloride levels as indicators of stress responses.

\section{Materials and Methods}

Silver carp fingerlings $(8.94 \pm 1.16 \mathrm{~cm}$; mean \pm SEM $)$ were obtained from Jagorany Chakra hatchery, Jessore. Fingerlings were well conditioned following methods practiced by the nursers. First, they were transferred from nursery to the conditioning pond $(40 \times$ $30 \mathrm{~m}$ ). After $24 \mathrm{hrs}$ in the conditioning pond, the fingerlings were seined and confined in hapas (size: $5 \mathrm{~m}^{2} ; 200 \mathrm{~g} / \mathrm{m}^{2}$ ) with manual aeration (water splashing) for 30 minutes every morning for 5 days $^{(7)}$. After 30 minutes of aeration, the fingerlings were released back into the conditioning pond. The fingerlings were fed daily wet mustard oil cake (MOC) at $2 \%$ body weight (BW) and suspended feeding $24 \mathrm{hrs}$ before loading for transport.

Nine aluminum vessels (20 litre) were filled with well water, pond water, and the mixture of well and pond water $(1: 1)$. Each vessel was stocked with $4 \mathrm{~kg}$ fingerlings at $400 \mathrm{~g} /$ for simulation. During simulation $1 / 3$ of the medium was changed at $1.5 \mathrm{hrs}$ interval from each experimental unit to maintain good water quality.

A $3 \times 4$ factorial design was used with three replicates. The experimental variables were transport medium and duration (1, 3, 6 and $9 \mathrm{hrs})$. The media were given manual aeration by hand agitation. Mortality, plasma cortisol and chloride levels were measured as the indicators of stress responses. Dissolved oxygen (DO), temperature and $\mathrm{pH}$ were also monitored before and after loading at different periods in the transport vessels.

Blood samples ( $\mathrm{n}=10)$ were drawn before loading as control (0 time), and 1, 3, 6 and $9 \mathrm{hrs}$ after transport. Dead fingerlings were removed and counted to determine the mortality, and water quality variables were also monitored at the time of fingerling 
sampling. After each sampling of fingerlings, the water volume was adjusted to maintain the initial loading density.

Dissolved oxygen and water temperature were measured using a portable DO meter (HACH sension 6, Loveland, CO, USA), and pH using a pH and ISE meter (Orion $290 \mathrm{~A}$ plus, Boston/Baverly, MA, USA).

Benzocaine $100 \mathrm{mg} \Lambda$ was used to anesthetize fingerlings before blood collection. Blood was pooled from each treatment into EDTA (100 g $/$ ) heparinized disposable (2.5 $\mathrm{ml}$ ) syringes by severing the caudal peduncle. After collection the blood was stored into vials on the ice for $1 \mathrm{hr}$ and centrifuged at $5000 \times g$ for $5 \mathrm{~min}$ using microcentrifuge. The supernatant plasma was frozen at $-20^{\circ} \mathrm{C}$ until analyzed. The plasma cortisol and chloride levels were measured following Hasan and Bart(7).

Mortality rate data were transformed into square root before statistical analysis. Treatment means between media and duration were compared using ANOVA followed by Tukey's HSD post hoc for multiple comparisons. Statistical software SPSS version 10.0 was used to analyze the data with the level of significance at $\mathrm{p}<0.05$.

\section{Results and Discussion}

In comparing the medium treatments until $6 \mathrm{hrs}$, the level of mortality was low. At 9 hrs, across all treatment media, mortality was very high (WW: 61\%; PW: 49\%; WPW: $60 \%$ ) without significant differences (Table 1). Cumulative mortality shows the total mortality in all three media $9 \mathrm{hrs}$ after transport in which the levels were also similar (WW: 68\%; PW: 54\%; WPW: 68\%). The observed low mortality until 6 hrs of transport indicates less effects of stress at life threatening level. Although silver carp fingerlings are sensitive to transport, the observed low mortality is surprising. Conditioning for 5 days could be the main reason responsible for this low mortality during the first $6 \mathrm{hrs}$. This psychological training could have helped the fingerlings to maintain homeostasis, increase relative fitness to encounter the emergency and shocks, to cope better with the stressors and adapt the challenge. Survival is compromised by exhaustion if the compensation for adapting is high( ${ }^{(8,9)}$. Another reason of this low mortality could be explained by maintaining the water quality variables in particular the concentration of DO within tolerance limit through water change at every $1.5 \mathrm{hrs}$. The observed very high mortality at 9 hrs in all three media (WW: $68.28 \pm 8.85 \%$; PW: $54.00 \pm 3.81 \%$; WPW: $68.27 \pm$ $13.63 \%$ ) could have resulted from the depletion of DO concentration. However, similar mortalities across all three media suggest the suitability of these three media free from pollution for transporting carp fingerlings with periodic change. Nabi et al.(6) observed $24.00 \pm 5.96 \%$ mortality in the mixed carp fry using river water as the transport medium in a simulation laboratory-experiment whereas the WW and PW resulted in $11.08 \pm 3.91$ and $15.50 \pm 4.95 \%$ mortality $24 \mathrm{hrs}$ after simulation at a very low loading density (6.85 $\mathrm{g} /$ ). However, they did not mention the water change and means of aeration including 
the conditioning of the fry. Samson and Macintosh(5) demonstrated that while unconditioned silver carp fry $(0.25 \mathrm{~g})$ resulted in $6.45 \%$ mortality when used well water, but pond water had $15 \%$ mortality 3 hrs after closed transport with compressed oxygen.

Table 1. Mortality and cumulative mortality rates (\%) in silver carp, H. molitrix fingerlings sampled 1, 3, 6 and 9 hrs after simulation transport using WW, PW and WPW $(1: 1)$ by hand agitation.

Mortality

Duration Levels of mortality (\%) sampled in three transport

(hrs) media

\begin{tabular}{llll}
\cline { 2 - 4 } & WW & PW & WPW \\
\hline 1 & $0.074 \pm 0.74^{\mathrm{b}}$ & $0.65 \pm 0.65^{\mathrm{b}}$ & $0.61 \pm 0.61^{\mathrm{b}}$ \\
3 & $1.45 \pm 0.35^{\mathrm{b}}$ & $0.68 \pm 0.68^{\mathrm{b}}$ & $3.17 \pm 2.09^{\mathrm{b}}$ \\
6 & $4.68 \pm 1.27^{\mathrm{b}}$ & $3.46 \pm 1.98^{\mathrm{b}}$ & $4.48 \pm 2.06^{\mathrm{b}}$ \\
9 & $60.66 \pm 8.87^{\mathrm{a}}$ & $49.20 \pm 3.58^{\mathrm{a}}$ & $59.73 \pm 10.21^{\mathrm{a}}$ \\
\hline \multicolumn{3}{c}{} & \\
\hline \multicolumn{1}{l}{ Cumulative mortality } & $0.65 \pm 0.65^{\mathrm{b}}$ & $0.61 \pm 0.61^{\mathrm{b}}$ \\
3 & $0.074 \pm 0.74^{\mathrm{b}}$ & $1.13 \pm 0.67^{\mathrm{b}}$ & $4.11 \pm 2.54^{\mathrm{b}}$ \\
6 & $2.19 \pm 0.65^{\mathrm{b}}$ & $4.80 \pm 1.33^{\mathrm{b}}$ & $8.54 \pm 3.43^{\mathrm{b}}$ \\
9 & $6.14 \pm 1.26^{\mathrm{b}}$ & $54.00 \pm 3.81^{\mathrm{a}}$ & $68.27 \pm 13.63^{\mathrm{a}}$ \\
\hline
\end{tabular}

Means $( \pm$ SEM) within column with different letters are significantly different (ANOVA, HSD; $\mathrm{p}$ <0.05).

Between treatment media when compared, while WPW resulted in the highest level of cortisol, WW had the lowest level (Table 2). The level of cortisol measured in the fingerlings sampled from $\mathrm{PW}$ was not different from those sampled from WW and WPW. In durations, 9 and $6 \mathrm{hrs}$ had significantly higher levels of cortisol than those of 3 and $1 \mathrm{hr}$. Cortisol level detected at $3 \mathrm{hrs}$ was higher than that of $1 \mathrm{hr}$. However, preloading cortisol level was similar to that of $1 \mathrm{hr}$ in all treatments. Although it is not clear for such variations in cortisol responses in different transport media, suspended particles for example, plankton and other particulate materials, and water temperature could be the underline reasons for these fluctuations. The observed high plasma cortisol levels at 6 and $9 \mathrm{hrs}$ could have resulted due to prolonged exposure in crowded condition ${ }^{(10)}$.

In WW, the levels of cortisol measured among durations were similar although the level of cortisol measured at $9 \mathrm{hrs}$ was significantly higher than that of control (Table 2). In PW, the highest level of cortisol was measured at 9 hrs while the lowest level was detected at $1 \mathrm{hr}$. However, the level of cortisol measured at $6 \mathrm{hrs}$ was not different from the levels found at 3 and 9 hrs. Similarly, the level of cortisol measured at $3 \mathrm{hrs}$ was similar to the levels observed at 1 and $6 \mathrm{hrs}$. The levels of cortisol in the fingerlings sampled among duration in WPW were similar to PW except the levels observed 
between 3 and $6 \mathrm{hrs}$ were different. The observed similar cortisol responses across all four duration treatments in WW could have resulted because of water change at every $1.5 \mathrm{hrs}$. The cortisol response in the fingerlings transported using PW indicates greater stress responses for prolonged haul. The level of cortisol measured in the fingerlings sampled form WPW observed was similar to PW. The reason for this similar cortisol response is unclear. The cortisol response in silver carp fingerlings is similar to the level (600 $\mathrm{ng} / \mathrm{ml}$ ) observed in striped bass, Morone saxatilis $5 \mathrm{hrs}$ after transport demonstrated by Mazik et al(11).

Table 2. Plasma cortisol (ng/ml) and chloride (meq/l) levels in silver carp, H. molitrix fingerlings sampled before loading and at 1, 3, 6 and 9 hrs using WW, PW and WPW $(1: 1)$ by hand agitation at $400 \mathrm{~g} / \mathrm{l}$.

\begin{tabular}{lcccc}
\hline \multirow{2}{*}{$\begin{array}{l}\text { Duration } \\
\text { (hrs) }\end{array}$} & \multicolumn{3}{c}{ Plasma cortisol in the fingerlings sampled in three } \\
transport media & \multirow{2}{*}{ Overall mean } \\
\cline { 2 - 4 } & WW & PW & WPW & \\
\hline Before loading & $181.45 \pm 36.90^{\mathrm{b}}$ & $181.45 \pm 36.90^{\mathrm{c}}$ & $181.45 \pm 36.90^{\mathrm{c}}$ & $181.45 \pm 18.45^{\mathrm{c}}$ \\
1 & $262.00 \pm 40.92^{\mathrm{ab}}$ & $228.00 \pm 20.13^{\mathrm{c}}$ & $187.00 \pm 32.02^{\mathrm{c}}$ & $225.67 \pm 19.40^{\mathrm{c}}$ \\
3 & $284.63 \pm 18.63^{\mathrm{ab}}$ & $336.90 \pm 29.25^{\mathrm{bc}}$ & $355.72 \pm 12.34^{\mathrm{b}}$ & $325.75 \pm 15.03^{\mathrm{b}}$ \\
6 & $358.15 \pm 31.98^{\mathrm{ab}}$ & $440.01 \pm 61.13^{\mathrm{ab}}$ & $552.85 \pm 41.54^{\mathrm{a}}$ & $450.33 \pm 36.56^{\mathrm{a}}$ \\
9 & $429.05 \pm 59.50^{\mathrm{a}}$ & $536.94 \pm 52.08^{\mathrm{a}}$ & $595.21 \pm 7.79^{\mathrm{a}}$ & $519.07 \pm 33.14^{\mathrm{a}}$ \\
\hline Overall mean & $333.47 \pm 26.29^{\mathrm{b}}$ & $385.21 \pm 39.37_{\mathrm{ab}}$ & $421.95 \pm 50.37 \mathrm{a}$ & $380.21 \pm 23.20$ \\
\hline Chloride & & & & \\
\hline Before loading & $102.67 \pm 12.91$ & $102.67 \pm 12.91^{\mathrm{a}}$ & $102.67 \pm 12.91^{\mathrm{a}}$ & $102.67 \pm 12.91^{\mathrm{a}}$ \\
1 & $98.67 \pm 1.76$ & $83.00 \pm 8.66^{\mathrm{ab}}$ & $86.00 \pm 1.00^{\mathrm{ab}}$ & $83.89 \pm 4.34^{\mathrm{ab}}$ \\
3 & $95.33 \pm 1.76$ & $72.00 \pm 3.78^{\mathrm{ab}}$ & $79.33 \pm 8.17_{\mathrm{ab}}^{\mathrm{ab}}$ & $70.44 \pm 4.05^{\mathrm{bc}}$ \\
6 & $76.33 \pm 11.89$ & $71.00 \pm 4.04^{\mathrm{ab}}$ & $74.33 \pm 7.80^{\mathrm{ab}}$ & $68.00 \pm 3.42^{\mathrm{bc}}$ \\
9 & $84.33 \pm 5.36$ & $66.33 \pm 1.20_{\mathrm{ab}^{\mathrm{b}}}$ & $51.67 \pm 8.29^{\mathrm{b}}$ & $61.78 \pm 5.01^{\mathrm{c}}$ \\
\hline Overall mean & $88.67 \pm 3.90_{\mathrm{a}}$ & $73.08 \pm 2.87^{\mathrm{b}}$ & $72.83 \pm 4.91_{\mathrm{b}}$ & $71.03 \pm 2.44$ \\
\hline
\end{tabular}

Means $( \pm$ SEM) within row with different subscript and column with superscript letters denote significant differences (ANOVA, HSD; $\mathrm{p}<0.05$ ).

Plasma chloride concentrations between treatment mediums were significantly different (Table 2). The highest level of chloride was measured in the fingerlings sampled from WW while the lowest level was detected in the fingerlings sampled from WPW. The level of chloride in the fingerlings sampled from PW was similar to that of WPW. In WW, the levels of chloride among durations, and between durations and control were similar. In $\mathrm{PW}$, the level of chloride measured at $9 \mathrm{hrs}$ was significantly lower than the preloading level. However, the levels of chloride detected at 1, 3, and $6 \mathrm{hrs}$ were similar to that of control. Among duration treatments the levels of chloride were similar. In WPW, 
the level of chloride had similar trends to PW. The observed high plasma chloride level in the WW could have resulted from low temperature, less or no turbidity and periodic change of water. However, the low chloride level measured in the fingerlings sampled from PW and WPW is not clear.

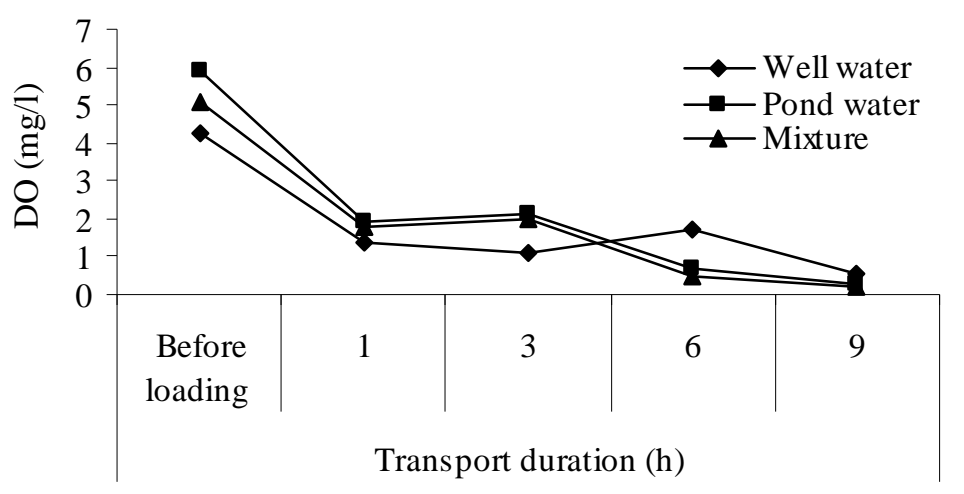

Fig. 1. Dissolved oxygen concentrations monitored before loading and 1, 3,6 and 9 hrs after transport in the vessels using well, pond and mixture of both in the transport of silver carp, Hypophthalmichthys molitrix fingerlings at $400 \mathrm{~g} /$. During simulation, $1 / \beta$ of the transport water was changed every $1.5 \mathrm{hrs}$ interval and given manual aeration.

In durations, $1 \mathrm{hr}$ after simulation treatment had significantly higher chloride level than the levels were observed in all other duration treatments. Nine hour resulted in the lowest level of chloride. However, pre-loading chloride level was significantly higher than those found in all other treatments except the first hour. Among durations, the levels of chloride measured $1 \mathrm{hr}$ after transport were similar. At $3 \mathrm{hrs}$, the level of chloride detected in WW was significantly higher than that of PW but similar to WPW. Similar trend of chloride was observed after 9 hrs except the level was lowest in WPW. After transport the levels of chloride declined throughout the experiment as expected ${ }^{(12,11,13,14)}$. However, in WW, chloride level dropped until 6 hrs and then resumed to increase. This resumption in the rise of chloride at $6 \mathrm{hrs}$ could be due to water change. In PW and WPW the levels of chloride had declining trend. The declining trend of chloride in PW and WPW during the later hours of transport could have resulted from low DO concentrations. Declining trends of chloride in the later hours in the fingerlings transported using PW and WPW indicates that water change in these two media did not help fingerlings to reduce their responses.

DO concentrations in all medium treatments were significantly lower than preloading level (Fig. 1). Level of DO at 9 hrs in WW, at 6 and 9 hrs in PW and WPW was lower than $1.0 \mathrm{mg} /$. In all other treatments $\mathrm{DO}$ was above $1.0 \mathrm{mg} /$. The water 
temperatures ranged in WW 26.43 - 27.17; in PW 27.17 - 28.43; and in WPW 27.03 $27.60^{\circ} \mathrm{C}$. The $\mathrm{pH}$ was $7.22-7.54$ in WW; $7.27-7.86$ in PW and $7.35-7.59$ in WPW.

\section{Conclusion}

Well water, pond water and the mixture of both can be used for transporting well conditioned silver carp fingerlings for $6 \mathrm{hrs}$ with little mortality. Well water has positive effects in maintaining high plasma chloride level that is crucial for successful transport.

\section{Acknowledgements}

The authors would like to thank Dr. Amrit Bart for his inspiration and SUFER (Support for University Fisheries Education and Research) Project, DFID Bangladesh for their financial support to conduct this study.

\section{References}

1. DoF (Department of Fisheries) 2008. Fisheries Fortnight (Matshya Pakkahaya in Bengali). pp. 109.

2. Hasan M and AN Bart 2006. Carp seed traders in Bangladesh: Sources of livelihoods and vulnerability resulting from fish seed mortality. Asia-Pacific J. Rural Dev. 16: 101-124.

3. Lewis DJ, GD Wood and R Gregory 1996. Trading the silver seed. University Press Ltd., Dhaka1000, Bangladesh. pp. 199.

4. Hasan M 2009. Carp seed transport in Bangladesh. Asia-Pacific J. Rural Dev. 19(1): 155-168.

5. Sampson, DRT and DJ Macintosh 1986. Transportation of live carp fry in sealed polythene bags. Aquaculture 54: 123-127.

6. Nabi R, MA Hossain and S Rahman 1983 On the use of tube-well and pond water for transporting carp fry. Univ. J. Zool. Rajshahi Univ. 2: 25-28.

7. Hasan M and AN Bart 2007. Improved survival of rohu, Labeo rohita (Hamilton-Buchanan) and silver carp, Hypophthalmichthys molitrix (Valenciennes) fingerlings using low-dose quinaldine and benzocaine during transport. Aquaculture Res. 38(1): 50-58.

8. Mazeuad MM, F Mazeuad and EM Donaldson 1977. Primary and secondary effects of stress in fish: Some new data with a general review. Trans. Am. Fish. Soc. 106: 201-212.

9. Pickering AD 1993. Growth and stress in fish. Aquaculture 111: 51-63.

10. Pickering AD 1981. Introduction: the concepts of biological stress. In: Stress and fish. A. D. Pickering (eds.). pp. 1-9.

11. Mazik PM, BA Simco and NC Parker 1991. Influence of water hardness and salts on survival and physiological characteristics of striped bass during transport. Trans. Am. Fish. Soc. 120: $121-126$.

12. Carmichael GJ 1984. Long distance transport of intensively reared largemouth bass. The Prog. Fish-Cult. 46: 111-115. 
13. Acerete L, JC Balasch, E Espinosa, A Josa and L Tort 2004. Physiological responses in Eurasian perch (Perca fluviatilis) subjected to stress by transport and handling. Aquaculture 237: 167-178.

14. Urbinati EC, JS de Abreu, AC de Silva Camargo and MAL Parra 2004. Loading and transport stress of juvenile matrinxa (Brycon cephalus Characidae) at various densities. Aquaculture 229: 389-400.

(Manuscript received on 2 December, 2012; revised on 12 January, 2013) 